\title{
Are plant endogenous factors like ethylene modulators of the early oxidative stress induced by mercury?
}

\author{
M. Belén Montero-Palmero ${ }^{1,2}$, Cristina Ortega-Villasante' ${ }^{1}$, Carolina Escobar ${ }^{2}$ and Luis E. Hernández ${ }^{1 *}$ \\ ' Laboratory of Plant Physiology, Department of Biology, Universidad Autonoma Madrid, Madrid, Spain \\ 2 Plant Physiology, Department of Environmental Sciences, Universidad de Castilla-La Mancha, Toledo, Spain
}

\section{Edited by:}

Naser A. Anjum, University of

Aveiro, Portugal

Reviewed by:

Naser A. Anjum, University of

Aveiro, Portugal

Nafees A. Khan, Aligarh Muslim

University, India

*Correspondence:

Luis E. Hernández, Laboratory of Plant Physiology BS13, Department

of Biology, Universidad Autonoma

Madrid, Edif. Biológicas, C/Darwin 2,

Campus Universitario Cantoblanco,

28049 Madrid, Spain

e-mail: luise.hernandez@uam.es
The induction of oxidative stress is one of the quickest symptoms appearing in plants subjected to metal stress. A transcriptional analysis of the early responses of alfalfa (Medicago sativa) seedlings to mercury ( $\mathrm{Hg} ; 3 \mu \mathrm{M}$ for 3,6 and $24 \mathrm{~h}$ ) showed that up-regulation of genes responding to ethylene were up-regulated, a phytohormone known to mediate in the cellular redox homeostasis. In this mini-review we have compared these quick responses with two other concurrent transcriptomic analysis in Barrel medic (Medicago truncatula) and barley (Hordeum vulgare) under Hg stress. Besides ethylene, $A B A$, and jasmonate related genes were up-regulated, all of them are endogenous factors known to intervene in oxidative stress responses. The information obtained may target future work to understand the cellular mechanisms triggered by $\mathrm{Hg}$, enabling biotechnological approaches to diminish $\mathrm{Hg}$-induced phytotoxicity.

Keywords: ethylene, homeostasis, hormones, mercury, oxidative stress, transcription

\section{BACKGROUND}

Mercury $(\mathrm{Hg})$ is a natural component of the Earth crust that is released by mainly geothermal activity, but accumulates in land and water ecosystems, mainly as a consequence of different human activities, such as mining and industry (Nriagu, 1996; Järup, 2003). This represents a serious problem to the environment and risks for human health (Tchounwou et al., 2012) as occurs in the mining district of Almadén (Spain), which contains the largest deposits of $\mathrm{Hg}$ in the World, with soils heavily polluted which require in situ and economically feasible cleaning procedures (Millán et al., 2006). Different strategies to clean-up metal polluted soils have been developed; among them, phytoremediation is considered one of the most economic and environmental friendly procedures to restore soil fertility (Alkorta et al., 2004). This biotechnical approach relies on the innate capability of plants to uptake and to accumulate metals from the soil, but it requires plants able to tolerate $\mathrm{Hg}$ accumulation in their organs and to prevent the general oxidative damage induced by this metal (Cho and Park, 2000; Patra et al., 2004; OrtegaVillasante et al., 2005). The maintenance of the cellular redox homeostasis in cells, where antioxidant enzymes and metabolites ameliorate the accumulation of oxidant Reactive Oxygen Species (ROS), would modulate the final tolerance response to Hg (Rellán-Álvarez et al., 2006; Zhou et al., 2008; Sobrino-Plata et al., 2009). Cross-talk of oxidative stress signaling cascades and endogenous factors, like ethylene, jasmonate, auxin, or abscisic acid, is pivotal for plant acclimation to stress and development (Potters et al., 2007), where antioxidants modulate ROS production (Considine and Foyer, 2014). In particular, ethylene through the family of APETALA 2/Ethylene Response Element Binding Protein (AP2/EREBP) transcription factors is known to mediate in hormone and redox signaling processes in context of abiotic stresses (Dietz et al., 2010). Understanding the mechanisms controlling acclimation to hazardous environmental will help to optimize tolerance to $\mathrm{Hg}$ in plant cells, knowledge that has been elusive (Chen and Yang, 2012). However, recent research using improved transcriptomics is now paving the way to identify mechanisms involved in the early responses to $\mathrm{Hg}$, putatively involved in the tolerance to this toxic metal, in particular with regards to redox homeostasis.

\section{EARLY OXIDATIVE STRESS INDUCED BY METAL TOXCITY}

In spite of high concentration of $\mathrm{Hg}$ in polluted soils, only a modest amount is taken up by plants, a function of the predominant edaphic conditions (Xuexum and Linhai, 1991). Moreover, $\mathrm{Hg}$ translocation from roots to shoots occurs normally at low rates, and most toxic effects are found in roots (Boening, 2000). Mercury reduces dramatically the root growth, diminishes the nutrients uptake rates and enhances cell death, and induces an early oxidative burst (Cho and Park, 2000; Patra and Sharma, 2000; Patra et al., 2004; Ortega-Villasante et al., 2005). A strong lipid peroxidation and protein oxidation occurred after shortterm exposure to Hg in maize (Rellán-Álvarez et al., 2006) and pea plants (Cho and Park, 2000), which represent chronic toxic effects with several alterations in cellular functions, such as cross-linking at the cell wall that may led to its stiffening and cell growth inhibition (Cargnelutti et al., 2006). Localization of $\mathrm{Hg}$ in plant tissues using X-ray synchrotron imaging showed that this metal enter the plant at the root tip, and accumulates in the vascular bundle, where vascular parenchyma cells showed corrugated morphology probably due to water balance alteration (Carrasco-Gil et al., 2013).

The knowledge about physiological responses of plants exposed to $\mathrm{Hg}$ has increased in the last few years as $\mathrm{Hg}$, which has 
been compared frequently with the phytotoxicity caused by other toxic elements like Cd (Gallego et al., 2012). With regard to the induction of the oxidative burst, several authors observed alterations in antioxidant enzymes activities such as catalase (CAT), ascorbate peroxidase (APX), or superoxide dismutase (SOD) mainly in roots (Rellán-Álvarez et al., 2006; Zhou et al., 2008). Interestingly, $\mathrm{Hg}$-specific responses were found in the activity of glutathione reductase (GR), key enzyme to maintain the redox balance of glutathione (GSH) that is strongly inhibited by $\mathrm{Hg}$, while under Cd or As it is induced (Sobrino-Plata et al., 2009, 2013); enzyme that has been suggested recently as a biomarker of $\mathrm{Hg}$ accumulation (Sobrino-Plata et al., 2013). A significant and early induction of ROS, such as superoxide anion $\left(\mathrm{O}_{2}^{-}\right)$and hydrogen peroxide $\left(\mathrm{H}_{2} \mathrm{O}_{2}\right)$, has been observed in Brassica juncea plants exposed to $\mathrm{Hg}$ (Meng et al., 2011). Microscale experiments with alfalfa seedlings showed that the generation of ROS by $\mathrm{Hg}$ occurs within minutes (Ortega-Villasante et al., 2007), possibly associated with the induction of plasma membrane NADPHoxidases responsible of the accumulation of $\mathrm{H}_{2} \mathrm{O}_{2}$ in the root apoplast (Montero-Palmero et al., 2014). This mechanism of ROS production may differ from that of triggered by Cd, possibly more related with mitochondrial electron transfer chain malfunction (Heyno et al., 2008). The Respiratory Burst Oxidase Homolog (Rboh)/NADPH-oxidases in plants has been reported as regulatory mechanisms of biotic and abiotic stress mediating in ROS production. Recently, the characterization of Arabidopsis RbohD, RbohF, and RbohC family members has been useful to understand better their role under stress conditions using atrbohD/atrbohF and atrbohC mutant plants, which demonstrated their relevance in the signaling network involved in stress cellular homeostasis (Torres and Dangl, 2005). In this sense, Arabidopsis atrbohD/atrbohF mutants and a 35S::AtrbohD overexpressor suggest the involvement of Rboh/NADPH-oxidases in the generation of $\mathrm{H}_{2} \mathrm{O}_{2}$ under $\mathrm{Hg}$ stress (Montero-Palmero et al., 2014).

ROS are considered as components of a signal cascade capable of triggering the induction of defense genes to cope with abiotic and biotic stresses. For example, Mittler et al. (2004) reviewed a list of more than 150 genes in Arabidopsis that participate in a complex network to regulate ROS levels after an oxidative burst. The identification of common components in the stress responses as key factors of cell homeostasis has been a major research effort recently (Kreps et al., 2002). Among others, the zinc-finger superfamily of transcription factors are one of the best functionally characterized group, which mediates in both biotic and abiotic stresses (Kodaira et al., 2011; Figueiredo et al., 2012). In this sense, the transcription factor Zat12 may canalize the oxidative burst signaling in Arabidopsis, as was observed when the tolerance was altered by interfering the expression of genes regulated by Zat12 (Davletova et al., 2005b). This regulatory role was shared with WRKY transcription factors, which are thought to regulate the expression of several stress-related genes, such as those encoding several APXs (Davletova et al., 2005a; Vanderauwera et al., 2005; Miao and Zentgraf, 2007; Chen et al., 2012).

Consistent with some physiological symptoms of $\mathrm{Hg}$ stress, changes in the transcription of genes needed for the regeneration of the photosynthetic apparatus and antioxidant enzymes were detected in Arabidopsis thaliana and tomato seedlings exposed to
Hg (Cho and Park, 2000; Heidenreich et al., 2001). Similarly, there was an up-regulation of genes encoding peroxidases, NADHdehydrogeneases and enzymes of the sulfur assimilatory pathway, as well as genes involved in secondary metabolism in $\mathrm{Hg}$ treated pea plants (i.e., biosynthesis of salicylic acid (SA) and isoflavonoids; Sävenstrand and Strid, 2004). Additionally, heme oxygenases (HOs) may mediate in the $\mathrm{Hg}$-related responses in Brassica napus (Shen et al., 2011), which are related with pathogenesis related proteins or small heat shock proteins (SHSPs) (Didierjean et al., 1996; Wollgiehn and Neumann, 1999).

Recent evidences suggest that metal homeostasis depend on a complex crosstalk between different signaling processes, where ROS signals are integrated with phytohormones signaling. Therefore, ROS are considered as important clues for development and ontogeny of plant cells (Mittler et al., 2011). It is possible that hormone and ROS signaling are playing their role at the same level in the stress response (Fujita et al., 2006), but they could also be involved in different steps of signaling cascade. Thus, phytohormones could alter ROS production or, in the contrary, ROS could be promoting the hormone cascade activation (Bartoli et al., 2013). Therefore, more complete studies of massive transcriptional analysis are required to understand the complex levels of responses normally studied using a heuristic incomplete approach, which has been recently undertaken as discussed below.

\section{CHARACTERIZATION OF THE MASSIVE TRANSCRIPTIONAL PATTERN UNDER Hg STRESS}

Recent bioinformatics and technological advances based on "omics" research have revitalized the integration at the transcriptional level of many physiological processes in plants (Mochida and Shinozaki, 2011). In this sense, DNA microarrays technology is a powerful tool used widely in the last decades after genome sequencing projects, that are enabling a more complete understanding of the global transcriptional changes under different environmental conditions and effectors, endogenous signals, interaction with pathogens, and so on (Amaratunga et al., 2014). With regard to metal homeostasis, a substantial effort has been done to characterize the primary cellular mechanisms involved in the heavy metal stress perception and defense mechanisms using different RNA-DNA microarray technologies. Arabidopsis DNA chips have been used to identify global transcriptional pattern in response to metals such as $\mathrm{Zn}$ (Becher et al., 2004), As (Abercrombie et al., 2008) or Cd (Herbette et al., 2006; Weber et al., 2006); where in most cases the transcriptional response of Arabidopsis thaliana has been compared with that of the metalliferous Arabidopsis halleri. Transcriptional activity of the metal Zn/Cd accumulator Noccaea (Thlaspi) caerulescens has also been compared with Arabidopsis in response to Cd (Van De Mortel et al., 2008). Apart from Arabidopsis, sensitive and tolerant cultivars of rice (Oryza sativa) have been used to assess their transcriptional response to As (Norton et al., 2008; Chakrabarty et al., 2009; Huang et al., 2012; Yu et al., 2012), Cu (Sudo et al., 2008) using different DNA microarray platforms. In addition, the transcriptional responses of Cd were compared with those of essential trace micronutrients like $\mathrm{Cu}$ in Arabidopsis (Zhao et al., 2009) or in rice roots (Lin et al., 2013). 
With respect to $\mathrm{Hg}$, three very recent concurrent studies were completed to characterize the massive transcriptional profile in seedlings of Medicago sativa (Montero-Palmero et al., 2014), Medicago truncatula (Zhou et al., 2013), and Hordeum vulgare (Lopes et al., 2013). The main purpose of these transcriptional studies was to obtain a comprehensive understanding of the metabolic pathways involved in the $\mathrm{Hg}$-stress response, which would shed light in the tolerance mechanisms involved. Genes encoding enzymes of the plant secondary metabolism, and other known to participate in biotic and abiotic stresses genes were differently expressed in the three transcriptomic studies performed with different plant species. For example, there was a clear up-regulation of genes encoding enzymes of the lignin biosynthesis pathway, such as those producing lignin precursors like coumarins, caffeoyl, and other monolignols (Table 1). It is known that lignin polymerization promotes cell wall stiffening (Passardi et al., 2004); lignin cross-linking reactions that may be responsible of the observed rapid root growth inhibition under Hg stress (Ortega-Villasante et al., 2007; Montero-Palmero et al., 2014). In addition, these phenolic metabolites are known antioxidants under metal stress conditions (Van De Mortel et al., 2008), which would counteract the rapid ROS induction by $\mathrm{Hg}$ Moreover observed in our experiments (Ortega-Villasante et al., 2007; Montero-Palmero et al., 2014). Other strongly regulated genes, common to all three plant species, fall in several stressrelated categories such as glutathione-S-transferases, heat shock proteins or pathogenesis related proteins (Table 1). It is thought that toxic metabolites, protein instability and other alterations in the cellular components may compromise cell survival in plants subjected to different types of environmental stresses (Mittler et al., 2011), indicating that a general unspecific response is also triggered by Hg. Interestingly, several phytohormone signaling pathways seemed to operate under $\mathrm{Hg}$ stress: ethylene, ABA and auxin related genes are among those significantly up-regulated after a short-term treatment (Table 1), which may be key players in metal perception and homeostasis.

Table 1 | Number of DEGs and percentages obtained from the total DEGs number in different functional categories.

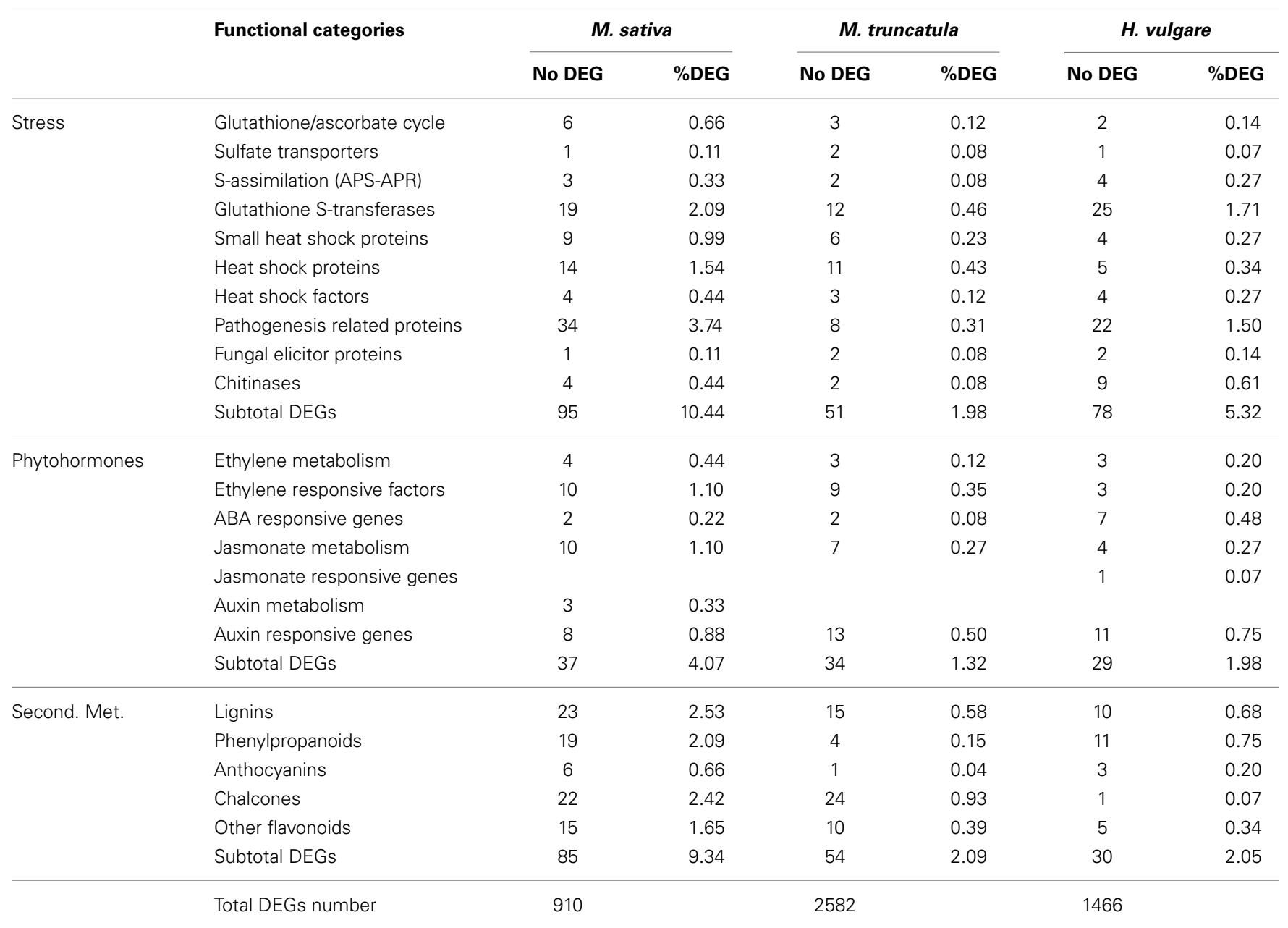

Differential expressed genes (DEGs) from the microarray of Medicago sativa root-seedlings exposed to $3 \mu \mathrm{M} \mathrm{Hg}$ during 3, 6, or 24h (FDR < 0.01), compared to the transcriptomics analyses made in Medicago truncatula seedlings treated with $10 \mu \mathrm{M} \mathrm{HgCl}_{2}$ during 6, 12, 24, and 48 h (FDR <0.001; Fold Change over 1) and in Hordeum vulgare root-seedlings exposed to approximately $300 \mu \mathrm{M}$ Hgin sand semi-hydroponics for 15 days $(P<0.05)$, and classified into the main functional MapMan categories. 


\section{INVOLVEMENT OF ETHYLENE IN THE OXIDATIVE BURST INDUCED BY Hg}

Plant cells exposed to toxic metals experience drastic metabolic changes, ranging from primary signaling events, biochemical and metabolic responses to transcriptional activation, as outlined in Figure 1A. An important feature of the early responses to toxic metals is the induction of ROS accumulation and oxidative stress (Baier et al., 2005), which occur minutes after the exposure of root epidermal cells to $\mathrm{Cd}$ and $\mathrm{Hg}$ (Hernández et al., 2012). Metal perception by plant cells is normally accomplished by a stress signaling network that would involve the activation of a Ca-signaling cascade (DalCorso et al., 2010), accumulation of ROS and reactive nitrogen species (RNS; i.e., nitric oxide or NO), or with the accumulation of certain stress-related phytohormones like salicylic, jasmonate and oxylipins (Rodríguez-Serrano et al., 2009; Tamás et al., 2010). Downstream signaling events include changes in the activity of several antioxidant enzymes, such as APX, GR, or SOD, along with modified concentration of antioxidant metabolites, such as ascorbate and GSH (Jozefczak et al., 2012), activation of Ca-dependent calmodulins, and mitogen-activated protein kinases (MAPKs; Jonak et al., 2004; Ye et al., 2013). Ethylene accumulated in Brassica juncea leaves when exposed to $\mathrm{Ni}$ and $\mathrm{Zn}$, phytohormone that promoted the activation of APX and GR enzymatic activities and augmented the pool of reduced GSH, conceivably required to enhance the antioxidant defensive barriers against metal stress (Khan and Khan, 2014). On the other hand, ethylene mediates in the assimilation process and the nutrition balance of sulfur, a fundamental macronutrient for plant acclimation to stress via GSH metabolism (Iqbal et al., 2013). The defenses to metal stress also comprise transcriptional changes, necessarily orchestrated by certain families of transcription factors, in particular some responding to ethylene, ABA, jasmonate, or auxin (i.e., ERF/AP2, WRKY, MYB, and ARF, respectively), that would recognize different cis-DNA regulatory motifs to control the transcription of genes involved in metal detoxification and tolerance (Thapa et al., 2012; Figure 1B). Expression of different metal transporters (for example the HMA1-4 and CDF families), enzymes of sulfur metabolism and GSH biosynthesis, and SHSPs are among the cellular defenses activated upon the commented transcriptional activation (Gallego et al., 2012; Figure 1).

Stress related phytohormones like SA or jamonate (derived from oxylipins) are known effectors that modulate responses to toxic metals (Xiang and Oliver, 1998; Zhou et al., 2009). In fact, several hormone responsive genes and genes involved in hormones synthesis are up-regulated, indicating that phytohormones play an important role in the Hg-induced response (Table $\mathbf{1}$ ). SA, brassinosteroids, cyotokinins, gibberellins, or IAA have been described stimulating the antioxidant response in terrestrial and aquatic plants exposed to $\mathrm{Cd}, \mathrm{Cu}$, or $\mathrm{Pb}$ (Hayat et al., 2007; Noriega et al., 2012; Piotrowska-Niczyporuk et al., 2012). On the contrary, jasmonate is known to trigger ROS production under metal stress (Maksymiec and Krupa, 2006), and accumulated in leaves of Arabidopsis and Phaseolous coccineus under $\mathrm{Cu}$ and Cd stress (Maksymiec et al., 2005). Interestingly, jasmonateinduced ROS is mediated by the oxidative status of GSH, as has been shown in GR defective mutants (Mhamdi et al., 2010). Subsequently, the transcriptional activity due to jasmonate has been recently associated with the oxidative burst led by changes in the redox potential of GSH in plant cells (Han et al., 2013). In addition, jasmonate entwines with ethylene in a complex signaling cascade that results in ROS production (Mittler, 2006). The stress response induced by ethylene may be associated with the jasmonate pathway, mediated by the COI1-jasmonate receptor as was shown in the root meristematic activity (Adams and Turner, 2010). This draws a rather complex picture where redox unbalance in the cell is required in turn for cysteine and GSH synthesis, possibly as part of a positive feedback mechanism where jasmonate or ethylene may intervene (Queval et al., 2009).

Ethylene plays also a complex role along with ROS in the defense responses to biotic and abiotic stresses (Mittler et al., 2011). Insensitive plants to ethylene, such as Arabidopsis ein25 , were unable to promote the oxidative burst after a pathogen elicited response (De Jong et al., 2002), highlighting the contribution of this phytohormone in the oxidative burst that precedes plant immune responses (Mersmann et al., 2010). This hormone could also interfere in the ROS signaling in Arabidopsis exposed to $\mathrm{Cu}$ and $\mathrm{Cd}$ (Arteca and Arteca, 2007) and $\mathrm{Al}$ (Sun et al., 2010). Moreover, the Hg-induced release of $\mathrm{H}_{2} \mathrm{O}_{2}$ by roots was attenuated when the ethylene perception was blocked in alfalfa and Arabidopsis seedlings, implying that ethylene is required by the activation of NADPH-oxidases to generate ROS under metal stress (Montero-Palmero et al., 2014).

Ethylene is also a phytohormone that determines root architecture and controls defense responses of plants to stress (Swarup et al., 2007). The rapid root growth inhibition observed under Hg (Ortega-Villasante et al., 2007) was counteracted when ethylene perception was blocked in alfalfa and Arabidopsis, implying a direct relationship between this phytohormone and the root architecture (Montero-Palmero et al., 2014). It is feasible that this role occurs under other metal stress conditions, as it was shown that ethylene synthesis antagonists alleviated the Alinduced arrest of root elongation (Tian et al., 2014). This control is exerted in combination of other hormones like auxins, salicylic acid, jasmonate, $\mathrm{ABA}$, or strigolactones, contributing to a general mechanism of tolerance and resistance to a wide range of biotic and abiotic stresses (Bari and Jones, 2009). For instance, a downstream regulation of auxin-related genes (such as YUCCA, PIN, or ARF), and cell cycle related-genes (CDKs and cyclins), are also interconnected with a $\mathrm{H}_{2} \mathrm{O}_{2}$ signaling cascade under $\mathrm{Cd}$ stress in rice plants (Zhao et al., 2012) and barley roots (Liptakova et al., 2012). Interestingly, there are clear evidences that auxins accumulation in roots depends partially on ethylene metabolism, which may affect ultimately the architecture of roots by promoting the appearance of secondary roots emergence (Ruzicka et al., 2007; Swarup et al., 2007). Uptake of mineral nutrients and exudation of malate could be also modulated by ethylene and auxin, possibly via a transcriptional regulation, which could be related with root architecture under metal stress (Tian et al., 2014). Similarly, jasmonate mediates in ASA1 expression, a protein involved in auxin synthesis and distribution-related, which also modulates root development (Wasternack and Hause, 2013). All these endogenous factors would interact with oxidative stress promoted signaling, composing a complex transduction network that regulates cell division, expansion, and ultimately root 


\section{A}

\section{RE S P O N S E}

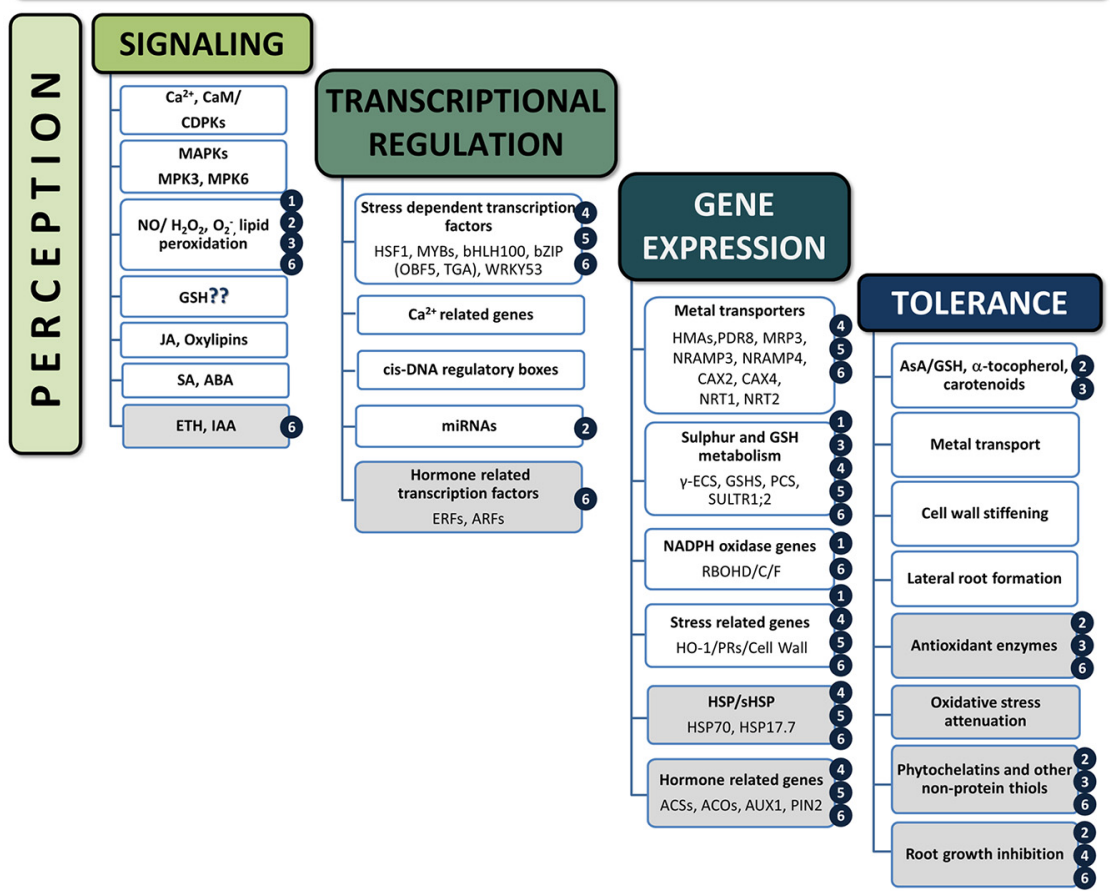

B

$\mathrm{HM}^{2+}$ APOPLAST

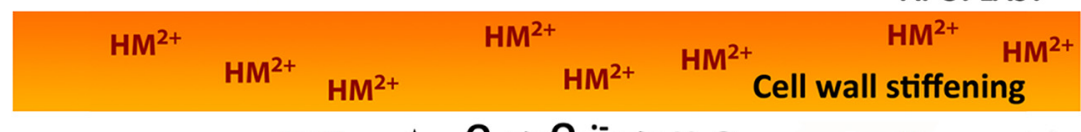

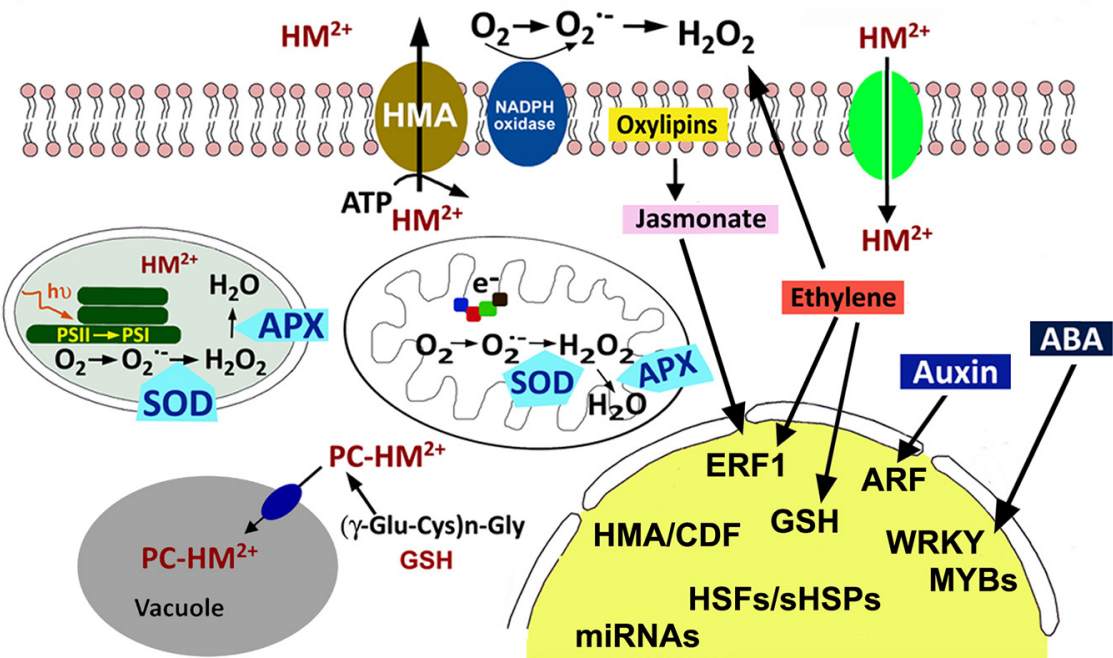

FIGURE 1 | (A) Sequence of events occurring upon metal exposure. Known events that appeared in plants treated with metals, with emphasis in those triggered by $\mathrm{Hg}$ (shaded boxes). For more information, refer to the following literature: (1) Lin et al., 2013; (2) Zhou et al., 2007, 2008; (3) Sobrino-Plata et al., 2009; Sobrino-Plata et al., 2014a,b; (4) Lopes et al., 2013; (5) Zhou et al., 2013; (6) Montero-Palmero et al., 2014. (B) Cellular responses in plants treated with metals (divalent toxic metal cation; $\mathrm{HM}^{2+}$ ). Metal cations can interact with cell wall components and then enter the cytoplasm via ion $\mathrm{Ca}^{2+}$ channels or active transporters (HMA). Once inside the cell, ROS production $\left(\mathrm{H}_{2} \mathrm{O}_{2}\right.$ or $\left.\mathrm{O}_{2}^{-}\right)$is induced possibly by NADPH-oxidases, in addition with electron transfe reactions in the chloroplast and mitochondria. Metals may be chelated with phytochelatins (PC) before are transferred to the vacuole. Antioxidant enzymes, such as catalase (CAT), superoxide dismutase (SOD), and ascorbate peroxidases (APX), are activated to maintain the cellular redox homeostasis. At the transcriptional level, the expression of certain stress genes (i.e., heat shock proteins, pathogen related proteins, or cell wall stiffening) is up-regulated, including stress-related transcription factors, antioxidantant proteins, microRNAs, and sulfur metabolism related genes. ROS/phytohormones crosstalk in response to metal stress would modulate the overall transcriptional profile, promoting the expression of the corresponding transcription factors. 
architecture (Considine and Foyer, 2014), which would be altered in plants exposed to toxic metals.

\section{FUTURE PERSPECTIVES AND CHALLENGES}

Current evidences support the concept that phytohormones are playing a significant role in the perception and response to toxic metals, possibly by interacting with a ROS-dependent signaling pathway. Being said that, the current understanding of the crosstalk between phytohormones and ROS networks is still obscure and very limited. Thus, future work should be directed to describe in detail the genetic network that regulates the perception of the stress induced by metals, and how different phytohormones and signaling components interact using the available collection of mutants with inhibited or blocked receptors, together with current massive transcriptomic profile analyses, and bioinformatic tools to obtain an integrated picture. This will allow the development of biotechnical strategies to enhance tolerance of plants to metal toxicity.

\section{ACKNOWLEDGMENTS}

This work was funded by the Ministry of Economy and Competitiveness (Project PROBIOMET AGL2010-15151), Junta Comunidades Castilla-La Mancha (FITOALMA2, POII10-0076458), and Comunidad de Madrid (EIADES consortium S2009/ AMB-1478).

\section{REFERENCES}

Abercrombie, J., Halfhill, M., Ranjan, P., Rao, M., Saxton, A., Yuan, J., et al. (2008). Transcriptional responses of Arabidopsis thaliana plants to As (V) stress. BMC Plant Biol. 8:87. doi: 10.1186/1471-2229-8-87

Adams, E., and Turner, J. (2010). COI1, a jasmonate receptor, is involved in ethylene-induced inhibition of Arabidopsis root growth in the light. J. Exp. Bot. 61, 4373-4386. doi: 10.1093/jxb/erq240

Alkorta, I., Hernández-Allica, J., Becerril, J. M., Amezaga, I., Albizu, I., and Garbisu, C. (2004). Recent findings on the phytoremediation of soils contaminated with environmentally toxic heavy metals and metalloids such as zinc, cadmium, lead, and arsenic. Rev. Environ. Sci. Biotech. 3, 71-90. doi: 10.1023/B:RESB.0000040059.70899.3d

Amaratunga, D., Cabrera, J., and Shkedy, Z. (2014). Exploration and Analysis of DNA Microarray and Other High-Dimensional Data. New York, NY: John Wiley and Sons. doi: 10.1002/9781118364505

Arteca, R. N., and Arteca, J. M. (2007). Heavy-metal-induced ethylene production in Arabidopsis thaliana. J. Plant Physiol. 164, 1480-1488. doi: 10.1016/j.jplph.2006.09.006

Baier, M., Kandlbinder, A., Golldack, D., and Dietz, K. J. (2005). Oxidative stress and ozone: perception, signalling and response. Plant Cell Environ. 28, 1012-1020. doi: 10.1111/j.1365-3040.2005.01326.x

Bari, R., and Jones, J. D. G. (2009). Role of plant hormones in plant defence responses. Plant Mol. Biol. 69, 473-488. doi: 10.1007/s11103-008-9435-0

Bartoli, C. G., Casalongué, C. A., Simontacchia, M., Márquez-García, B., and Foyer, C. H. (2013). Interactions between hormone and redox signalling pathways in the control of growth and cross tolerance to stress. Environ. Exp. Bot. 94, 73-88. doi: 10.1016/j.envexpbot.2012.05.003

Becher, M., Talke, I. N., Krall, L., and Krämer, U. (2004). Cross-species microarray transcript profiling reveals high constitutive expression of metal homeostasis genes in shoots of the zinc hyperaccumulator Arabidopsis halleri. Plant J. 37, 251-268. doi: 10.1046/j.1365-313X.2003.01959.x

Boening, D. W. (2000). Ecological effects, transport, and fate of mercury: a general review. Chemosphere 40, 1335-1352. doi: 10.1016/S0045-6535(99)00283-0

Cargnelutti, D., Tabaldi, L., Spanevello, R., De Oliveira-Jucoski, G., Battisti, V., Redin, M., et al. (2006). Mercury toxicity induces oxidative stress in growing cucumber seedlings. Chemosphere 65, 999-1006. doi: 10.1016/j.chemosphere. 2006.03.037
Carrasco-Gil, S., Siebner, H., LeDuc, D., Webb, S. M., Millán, R., Andrews, J. C., et al. (2013). Mercury localization and speciation in plants grown hydroponically or in a natural environment. Environ. Sci. Tech. 47, 3082-3090. doi: 10.1021/es303310t

Chakrabarty, D., Trivedi, P. K., Misra, P., Tiwari, M., Shri, M., Shukla, D., et al. (2009). Comparative transcriptome analysis of arsenate and arsenite stresses in rice seedlings. Chemosphere 74, 688-702. doi: 10.1016/j.chemosphere.2008. 09.082

Chen, J., and Yang, Z.-M. (2012). Mercury toxicity, molecular response and tolerance in higher plants. Biometals 25, 847-857. doi: 10.1007/s10534-012-9560-8

Chen, L., Song, Y., Li, S., Zhang, L., Zou, C., and Yu, D. (2012). The role of WRKY transcription factors in plant abiotic stresses. Biochim. Biophys. Acta 1819, 120-128. doi: 10.1016/j.bbagrm.2011.09.002

Cho, U., and Park, J. (2000). Mercury-induced oxidative stress in tomato seedlings. Plant Sci. 156, 1-9. doi: 10.1016/S0168-9452(00)00227-2

Considine, M. J., and Foyer, C. H. (2014). Redox regulation of plant development. Antioxid. Redox Signal. doi: 10.1089/ars.2013.5665. [Epub ahead of print].

DalCorso, G., Farinati, S., and Furini, A. (2010). Regulatory networks of cadmium stress in plants. Plant Signal. Behav. 5, 663-667. doi: 10.4161/psb.5.6.11425

Davletova, S., Rizhsky, L., Liang, H., Shengqiang, Z., Oliver, D. J., Coutu, J., et al. (2005b). Cytosolic ascorbate peroxidase 1 is a central component of the reactive oxygen gene network of Arabidopsis. Plant Cell 17, 268-281. doi: 10.1105/tpc. 104.026971

Davletova, S., Schlauch, K., Coutu, J., and Mittler, R. (2005a). Role in reactive oxygen and abiotic stress signalling in Arabidopsis. Plant Physiol. 139, 847-856. doi: 10.1104/pp.105.068254

De Jong, A. J., Yakimova, E. T., Kapchina, V. M., and Woltering, E. J. (2002). A critical role for ethylene in hydrogen peroxide release during programmed cell death in tomato suspension cells. Planta 214, 537-545. doi: 10.1007/s004250100654

Didierjean, L., Frendo, P., Nasser, W., Genot, G., Marivet, J., and Burkard, G. (1996). Heavy-metal-responsive genes in maize: identification and comparison of their expression upon various forms of abiotic stress. Planta 199, 1-8. doi: 10.1007/BF00196874

Dietz, K. J., Vogel, M. O., and Viehhauser, A. (2010). AP2/EREBP transcription factors are part of gene regulatory networks and integrate metabolic, hormonal and environmental signals in stress acclimation and retrograde signalling. Protoplasma 245, 3-14. doi: 10.1007/s00709-010-0142-8

Figueiredo, D. D., Barros, P. M., Cordeiro, A. M., Serra, T. S., Lourenc, T., Chander, S., et al. (2012). Seven zinc-finger transcription factors are novel regulators of the stress responsive gene OsDREB1B. J. Exp. Bot. 63, 3643-3656. doi: 10.1093/ jxb/ers035

Fujita, M., Fujita, Y., Noutoshi, Y., Takahashi, F., Narusaka, Y., YamaguchiShinozaki, K., et al. (2006). Crosstalk between abiotic and biotic stress responses: a current view from the points of convergence in the stress signalling networks. Curr. Opin. Plant Biol. 9, 436-442. doi: 10.1016/j.pbi.2006.05.014

Gallego, S., Pena, L. B., Barcia, R. A., Azpilicueta, C. E., Iannonea, M. F., Rosales, E. P., et al. (2012). Unravelling cadmium toxicity and tolerance in plants: insight into regulatory mechanisms. Environ. Exp. Bot. 83, 33-46. doi: 10.1016/ j.envexpbot.2012.04.006

Han, Y., Mhamdi, A., Chaouch, S., and Noctor, G. (2013). Regulation of basal and oxidative stress-triggered jasmonic acid-related gene expression by glutathione. Plant Cell Environ. 36, 1135-1146. doi: 10.1111/pce.12048

Hayat, S., Ali, B., Aiman Hasan, S., and Ahmad, A. (2007). Brassinosteroid enhanced the level of antioxidants under cadmium stress in Brassica juncea. Environ. Exp. Bot. 60, 33-41. doi:10.1016/j.envexpbot.2006.06.002

Heidenreich, B., Mayer, K., Sandermann, H. J. R., and Ernst, D. (2001). Mercuryinduced genes in Arabidopsis thaliana: identification of induced genes upon long-term mercuric ion exposure. Plant Cell Environ. 24, 1227-1234. doi: 10.1046/j.0016-8025.2001.00775.x

Herbette, S., Taconnat, L., and Hugouvieux, V. (2006). Genome-wide transcriptome profiling of the early cadmium response of Arabidopsis roots and shoots. Biochimie 88, 1751-1765. doi: 10.1016/j.biochi.2006.04.018

Hernández, L. E., Ortega-Villasante, C., Montero-Palmero, M. B., Escobar, C., and Carpena, R. O. (2012). "Heavy metal perception in a microscale environment: a model system using high doses of pollutants," in Metal Toxicity in Plants: Perception, Signalling and Remediation, eds D. K. Gupta and L. M. Sandalio (Heidelberg: Springer), 23-39. doi: 10.1007/978-3-642-22081-4_2

Heyno, E., Klose, C., and Krieger-Liszkay, A. (2008). Origin of cadmiuminduced reactive oxygen species production: mitochondrial electron transfer 
versus plasma membrane NADPH-oxidase. New Phytol. 179, 687-699. doi: 10.1111/j.1469-8137.2008.02512.x

Huang, T. L., Nguyen, Q. T. T., Fu, S. F., Lin, C. Y., Chen, Y. C., and Huang, H. J. (2012). Transcriptomic changes and signalling pathways induced by arsenic stress in rice roots. Plant Mol. Biol. 80, 587-608. doi: 10.1007/s11103012-9969-Z

Iqbal, N., Trivellini, A., Masood, A., Ferrante, A., and Khan, N. A. (2013). Current understanding on ethylene signalling in plants: the influence of nutrient availability. Plant Physiol. Biochem. 73, 128-138. doi: 10.1016/j.plaphy.2013. 09.011

Järup, L. (2003). Hazards of heavy metal contamination. Br. Med. Bull. 68, 167-182. doi: $10.1093 / \mathrm{bmb} / \mathrm{ldg} 032$

Jonak, C., Nakagami, H., and Hirt, H. (2004). Heavy metal stress activation of distinct mitogen-activated protein kinase pathways by copper and cadmium. Plant Physiol. 136, 3276-3283. doi: 10.1104/pp.104.045724

Jozefczak, M., Remans, T., Vangronsveld, J., and Cuypers, A. (2012). Glutathione is a key player in metal-induced oxidative stress defenses. Int. J. Mol. Sci. 13, 3145-3175. doi: 10.3390/ijms13033145

Khan, M. I. R., and Khan, N. A. (2014). Ethylene reverses photosynthetic inhibition by nickel and zinc in mustard through changes in PS II activity, photosynthetic nitrogen use efficiency, and antioxidant metabolism. Protoplasma. doi: 10.1007/s00709-014-0610-7. [Epub ahead of print].

Kodaira, K. S., Qin, F., Phan-Tran, L. S., Maruyama, K., and Kidokoro, S. (2011). Arabidopsis Cys2/His2 zinc-finger proteins AZF1 and AZF2 negatively regulate abscisic acid-repressive and auxin-inducible genes under abiotic stress conditions. Plant Physiol. 157, 742-756. doi: 10.1104/pp.111.1826830

Kreps, J. A., Yajun, W., Hur-Song, C., Zhu, T., Wang, X., and Harper, J. E. (2002). Transcriptome changes for Arabidopsis in response to salt, osmotic, and cold stress. Plant Physiol. 130, 2129-2141. doi: 10.1104/pp.008532

Lin, C. Y., Trinh, N. N., Fu, S. F., Hsiung, Y. C., Chia, L. C., Lin, C. W., et al. (2013). Comparison of early transcriptome responses to copper and cadmium in rice roots. Plant Mol. Biol. 81,507-522. doi: 10.1007/s11103-013-0020-9

Liptakova, L., Bocova, B., Huttova, J., Mistrik, I., and Tamás, L. (2012). Superoxide production induced by short-term exposure of barley roots to cadmium, auxin, alloxan and sodium dodecyl sulfate. Plant Cell Rep. 31, 2189-2197. doi: 10.1007/s00299-012-1329-6

Lopes, M. S., Iglesia-Turiño, S., Cabrera-Bosquet, L., Serret, M. D., Bort, J., Febrero, A., et al. (2013). Molecular and physiological mechanisms associated with root exposure to mercury in barley. Metallomics 5, 1305. doi: 10.1039/c3mt00084b

Maksymiec, W., and Krupa, Z. (2006). The effects of short-term exposition to $\mathrm{Cd}$, excess $\mathrm{Cu}$ ions and jasmonate on oxidative stress appearing in Arabidopsis thaliana. Environ. Exp. Bot. 57, 187-194. doi: 10.1016/j.envexpbot.2005.05.006

Maksymiec, W., Wianowska, D., Dawidowicz, A. L., Radkiewicz, S., Mardarowicz, M., and Krupta, Z. (2005). The level of jasmonic acid in Arabidopsis thaliana and Phaseolus coccineus plants under heavy metal stress. J. Plant Physiol. 162, 1338-1346. doi: 10.1016/j.jplph.2005.01.013

Meng, D. K., Chen, J., and Yang, Z. M. (2011). Enhancement of tolerance of Indian mustard (Brassica juncea) to mercury by carbon monoxide. J. Hazard. Mater. 186, 1823-1829. doi: 10.1016/j.jhazmat.2010.12.062

Mersmann, S., Bourdais, G., Rietz, S., and Robatzek, S. (2010). Ethylene signaling regulates accumulation of the FLS2 receptor and is required for the oxidative burst contributing to plant immunity. Plant Physiol. 154, 391-400. doi: 10.1104/pp.110.154567

Mhamdi, A., Hager, J., Chaouch, S., Queval, G., Han, Y., Taconnat, L., et al. (2010). Arabidopsis GLUTATHIONE REDUCTASE1 plays a crucial role in leaf responses to intracellular hydrogen peroxide and in ensuring appropriate gene expression through both salicylic acid and jasmonic acid signalling pathways. Plant Physiol. 153, 1144-1160. doi: 10.1104/pp.110.153767

Miao, Y., and Zentgraf, U. (2007). The antagonist function of Arabidopsis WRKY53 and ESR/ESP in leaf senescence is modulated by the jasmonic and salicylic acid equilibrium. Plant Cell 19, 819-830. doi: 10.1105/tpc.106.042705

Millán, R., Gamarra, R., Schmid, T., Sierra, M. J., Quejido, A. J., Sánchez, D. M., et al. (2006). Mercury content in vegetation and soils of the Almadén mining area (Spain). Sci. Total Environ. 368, 79-87. doi: 10.1016/j.scitotenv.2005.09.096

Mittler, R. (2006). Abiotic stress, the field environment and stress combination. Trends Plant Sci. 11, 15-19. doi: 10.1016/j.tplants.2005.11.002

Mittler, R., Vanderauwera, S., Gollery, M., and Van Breusegem, F. (2004). Reactive oxygen gene network of plants. Trends Plant Sci. 9, 490-498. doi: 10.1016/j.tplants.2004.08.009
Mittler, R., Vanderauwera, S., Suzuk, N., Miller, G., Tognetti, V. B., Vandepoele, K., et al. (2011). ROS signalling: the new wave? Trends Plant Sci. 16, 1360-1385. doi: 10.1016/j.tplants.2011.03.007

Mochida, K., and Shinozaki, K. (2011). Advances in omics and bioinformatics tools for systems analyses of plant functions. Plant Cell Physiol. 52, 2017-2038. doi: $10.1093 /$ pcp/pcr153

Montero-Palmero, M. B., Martín-Barranco, A., Escobar, C., and Hernández, L. E. (2014). Early transcriptional responses to mercury: a role for ethylene in mercury-induced stress. New Phytol. 201, 116-130. doi: 10.1111/nph.12486

Noriega, G., Caggiano, E., Lecube, M. L., Santa-Cruz, D., Batlle, A., Tomaro, M., et al. (2012). The role of salicylic acid in the prevention of oxidative stress elicited by cadmium in soybean plants. Biometals 25, 1155-1165. doi: 10.1007/ s10534-012-9577-z

Norton, G. J., Lou-Hing, D. E., Meharg, A., and Price, A. (2008). Rice-arsenate interactions in hydroponics: whole genome transcriptional analysis. J. Exp. Bot. 59, 2267-2276. doi: 10.1093/jxb/ern097

Nriagu, J. O. (1996). History of global metal pollution. Science 272, 223-224. doi: $10.1126 /$ science. 272.5259 .223

Ortega-Villasante, C., Hernández, L. E., Rellán-Álvarez, R., Del Campo, F. F., and Carpena-Ruiz, R. O. (2007). Rapid alteration of cellular redox homeostasis upon exposure to cadmium and mercury in alfalfa seedlings. New Phytol. 176, 96-107. doi: 10.1111/j.1469-8137.2007.02162.x

Ortega-Villasante, C., Rellán-Álvarez, R., Del Campo, F. F., Carpena-Ruiz, R. O., and Hernández, L. E. (2005). Cellular damage induced by cadmium and mercury in Medicago sativa. J. Exp. Bot. 56, 2239-2251. doi: 10.1093/jxb/eri223

Passardi, F., Penel, C., and Dunand, C. (2004). Performing the paradoxical: how plant peroxidases modify the cell wall. Trends Plant Sci. 9, 534-540. doi: 10.1016/ j.tplants.2004.09.002

Patra, M., Bhowmik, N., Bandopadhyay, B., and Sharma, A. (2004). Comparison of mercury, lead and arsenic with respect to genotoxic effects of plant systems and the development of genetic tolerance. Environ. Exp. Bot. 52, 199-223. doi: 10.1016/j.envexpbot.2004.02.009

Patra, M., and Sharma, A. (2000). Mercury toxicity in plants. Bot. Rev. 66, 379-422. doi: $10.1007 / \mathrm{BF} 02868923$

Piotrowska-Niczyporuk, A., Bajguz, A., Zambrzycka, E., and GodlewskaZylkiewicz, B. (2012). Phytohormones as regulators of heavy metal biosorption and toxicity in green alga Chlorella vulgaris (Chlorophyceae). Plant Physiol. Biochem. 52, 52-65. doi: 10.1016/j.plaphy.2011.11.009

Potters, G., Pasternak, T. P., Guisez, Y., Palme, K. J., and Jansen, M. A. (2007). Stressinduced morphogenic responses: growing out of trouble? Trends Plant Sci. 12, 98-105. doi: 10.1016/j.tplants.2007.01.004

Queval, G., Thominet, D., Vanacker, H., Miginiac-Maslow, M., Gakière, B., and Noctor, G. (2009). $\mathrm{H}_{2} \mathrm{O}_{2}$-activated up-regulation of glutathione in Arabidopsis involves induction of genes encoding enzymes involved in cysteine synthesis in the chloroplast. Mol. Plant 2, 344-356. doi: 10.1093/mp/ ssp002

Rellán-Álvarez, R., Ortega-Villasante, C., Álvarez-Fernández, A., Del Campo, F. F., and Hernández, L. E. (2006). Stress responses of Zea mays to cadmium and mercury. Plant Soil 279, 41-50. doi: 10.1007/s11104-005-3900-1

Rodríguez-Serrano, M., Romero-Puertas, M. C., Pazmiño, D. M., Testillano, P. S., Risueño, M. C., del Río, L. A., et al. (2009). Cellular response of pea plants to cadmium toxicity: cross talk between reactive oxygen species, nitric oxide, and calcium. Plant Physiol. 150, 229-243. doi: 10.1104/pp.108.131524

Ruzicka, K., Ljung, K., Vanneste, S., Podhorska, R., Beeckman, T., Friml, J., et al. (2007). Ethylene regulates root growth through effects on auxin biosynthesis and transport-dependent auxin distribution. Plant Cell 19, 2197-2212. doi: 10.1105/tpc.107.052126

Sävenstrand, H., and Strid, A. (2004). Six genes strongly regulated by mercury in Pisum sativum roots. Plant Physiol. Biochem. 42, 135-142. doi: 10.1016/j.plaphy. 2003.11.005

Shen, Q., Jiang, M., Li, H., Che, L. L., and Yang, Z. M. (2011). Expression of a Brassica napus heme oxygenase confers plant tolerance to mercury toxicity. Plant Cell Environ. 34, 752-763. doi: 10.1111/j.1365-3040.2011.02279.x

Sobrino-Plata, J., Carrasco-Gil, S., Abadía, J., Escobar, C., Álvarez-Fernández, A., and Hernández, L. E. (2014a). The role of glutathione in mercury tolerance resembles its function under cadmium stress in Arabidopsis. Metallomics 29, 356-366. doi: 10.1039/c3mt00329a

Sobrino-Plata, J., Herrero, J., Carrasco-Gil, S., Pérez-Sanz, A., Lobo, C., Escobar, C., et al. (2013). Specific stress responses to cadmium, arsenic and mercury 
appear in the metallophyte Silene vulgaris when grown hydroponically. RSC Adv. 3, 4736-4744. doi: 10.1039/c3ra40357b

Sobrino-Plata, J., Meyssen, D., Cuypers, A., Escobar, C., and Hernández, L. E. (2014b). Glutathione is a key antioxidant metabolite to cope with mercury and cadmium stress. Plant Soil 377, 369-381. doi: 10.1007/s11104-0132006-4

Sobrino-Plata, J., Ortega-Villasante, C., Flores-Cáceres, M. L., Escobar, C., Del Campo, F. F., and Hernandez, L. E. (2009). Differential alterations of antioxidant defenses as bioindicators of mercury and cadmium toxicity in alfalfa. Chemosphere 77, 946-954. doi: 10.1016/j.chemosphere.2009.08.007

Sudo, E., Itouga, M., Yoshida-Hatanaka, K., Ono, Y., and Sakakibara, H. (2008). Gene expression and sensitivity in response to copper stress in rice leaves. J. Exp. Bot. 59, 3465-3474. doi: 10.1093/jxb/ern196

Sun, P., Tian, Q., Chen, J., and Zhang, W. (2010). Aluminium-induced inhibition of root elongation in Arabidopsis is mediated by ethylene and auxin. J. Exp. Bot. 61, 347-356. doi: 10.1093/jxb/erp306

Swarup, R., Perry, P., Hagenbeek, D., Van Der Straeten, D., Beemster, G. T. S., Sandberg, G., et al. (2007). Ethylene up regulates auxin biosynthesis in Arabidopsis seedlings to enhance inhibition of root cell elongation. Plant Cell 19, 2186-2196. doi: 10.1105/tpc.107.052100

Tamás, L., Mistrík, I., Huttová, J., Halušková, L., Valentovičová, K., and Zelinová, V. (2010). Role of reactive oxygen species-generating enzymes and hydrogen peroxide during cadmium, mercury and osmotic stresses in barley root tip. Planto 231, 221-231. doi: 10.1007/s00425-009-1042-z

Tchounwou, P. B., Yedjou, C. G., Patlolla, A. K., and Sutton, D. J. (2012). Heavy metal toxicity and the environment. EXS 101, 133-164. doi: 10.1007/978-37643-8340-4_6

Thapa, G., Sadhunkhan, A., Panda, S. K., and Sahoo, L. (2012). Molecular mechanistic model of plant heavy metal tolerance. Biometals 25, 489-505. doi: 10.1007/ s10534-012-9541-y

Tian, Q., Zhan, X., Ramesh, S., Gilliham, M., Tyerman, S. D., and Zhan, W.-H (2014). Ethylene negatively regulates aluminium-induced malate efflux from wheat roots and tobacco cells transformed with TaALMT1. J. Exp. Bot. 65 , 2415-2426. doi: 10.1093/jxb/eru123

Torres, M. A., and Dangl, J. (2005). Functions of the respiratory burst oxidase in biotic interactions, abiotic stress and development. Curr. Opin. Plant Biol. 8, 397-403. doi: 10.1016/j.pbi.2005.05.014

Van De Mortel, J., Henk, S., Moerland, P., Themaat, E., Van Der Ent, S., Blankestijn, H., et al. (2008). Expression differences for genes involved in lignin, glutathione and sulphate metabolism in response to cadmium in Arabidopsis thaliana and the related Zn/Cd hyperaccumulator Thlaspi caerulescens. Plant Cell Environ. 31, 301-324. doi: 10.1111/j.1365-3040.2007.01764.x

Vanderauwera, S., Zimmermann, P., Rombauts, S., Vandenabeele, S., Langebartels, C., Gruissem, W., et al. (2005). Genome-wide analysis of hydrogen peroxideregulated gene expression in Arabidopsis reveals a high light-induced transcriptional cluster involved in anthocyanin biosynthesis. Plant Physiol. 139, 806-821. doi: 10.1104/pp.105.065896

Wasternack, C., and Hause, B. (2013). Jasmonates: biosynthesis, perception, signal transduction and action in plant stress response, growth and development. An update to the 2007 review in Annals of Botany. Ann. Bot. 111, 1021-1058. doi: $10.1093 / \mathrm{aob} / \mathrm{mct} 067$

Weber, M., Trampczynska, A., and Clemens, S. (2006). Comparative transcriptome analysis of toxic metal responses in Arabidopsis thaliana and the $\mathrm{Cd}^{2+}$. hypertolerant facultative metallophyte Arabidopsis halleri. Plant Cell Environ. 29, 950-963. doi: 10.1111/j.1365-3040.2005.01479.x
Wollgiehn, R., and Neumann, D. (1999). Metal stress response and tolerance of cultured cells from Silene vulgaris and Lycopersicon peruvianum: role of heat stress proteins. J. Plant Physiol. 154, 547-553. doi: 10.1016/S0176-1617(99)80296-X

Xiang, C., and Oliver, D. J. (1998). Glutathione metabolic genes coordinately respond to heavy metals and jasmonic acid in Arabidopsis. Plant Cell 10, 1539-1550. doi: 10.1105/tpc.10.9.1539

Xuexum, Z., and Linhai, G. (1991). Studies on the heavy metals pollution of soil and plants in Tianjin waste-water irrigated area. Ekologia 10, 87-97.

Ye, Y., Li, Z., and Xing, D. (2013). Nitric oxide promotes MPK6-mediated caspase3 -like activation in cadmium-induced Arabidopsis thaliana programmed cell death. Plant Cell Environ. 36, 1-15. doi: 10.1111/j.1365-3040.2012.02543.x

Yu, L. J., Luo, Y. F., Liao, B., Xie, L. J., Chen, L., Xiao, S., et al. (2012). Comparative transcriptome analysis of transporters, phytohormone and lipid metabolism pathways in response to arsenic stress in rice (Oryza sativa). New Phytol. 195, 97-112. doi: 10.1111/j.1469-8137.2012.04154.x

Zhao, C. R., Ikka, T., Sawaki, Y., Kobayashi, Y., Suzuki, Y., Hibino, T., et al. (2009). Comparative transcriptomic characterization of aluminum, sodium chloride, cadmium and copper rhizotoxicities in Arabidopsis thaliana. BMC Plant Biol. 9:32. doi: 10.1186/1471-2229-9-32

Zhao, F. Y., Han, M. M., Zhang, S. Y., Wang, K., Zhang, C. R., Liu, T., et al. (2012). Hydrogen peroxide-mediated growth of the root system occurs via auxin signalling modification and variations in the expression of cell-cycle genes in rice seedlings exposed to cadmium stress. J. Integr. Plant Biol. 54, 991-1006. doi: 10.1111/j.1744-7909.2012.01170.x

Zhou, Z. S., Guo, K., Elbaz, A. A., and Yang, Z. M. (2009). Salicylic acid alleviates mercury toxicity by preventing oxidative stress in roots of Medicago sativa. Environ. Exp. Bot. 65, 27-34. doi: 10.1016/j.envexpbot.2008.06.001

Zhou, Z. S., Huang, S. Q., Guo, K., Mehta, S. K., Zhang, P. C., and Yang, Z. M. (2007). Metabolic adaptations to mercury-induced oxidative stress in roots of Medicago sativa L. J. Inorg. Biochem. 101, 1-9. doi: 10.1016/j.jinorgbio.2006. 05.011

Zhou, Z. S., Wang, S. J., and Yang, Z. M. (2008). Biological detection and analysis of mercury toxicity to alfalfa (Medicago sativa) plants. Chemosphere 70, 1500-1509. doi: 10.1016/j.chemosphere.2007.08.028

Zhou, Z. S., Yang, S. N., Li, H., Zhu, C. C., Liu, Z. P., and Yang, Z. M. (2013). Molecular dissection of mercury-responsive transcriptome and sense/antisense genes in Medicago truncatula by high-throughput sequencing. J. Hazard. Mater. 252, 123-131. doi: 10.1016/j.jhazmat.2013.02.011

Conflict of Interest Statement: The authors declare that the research was conducted in the absence of any commercial or financial relationships that could be construed as a potential conflict of interest.

Received: 26 May 2014; accepted: 16 July 2014; published online: 08 August 2014. Citation: Montero-Palmero MB, Ortega-Villasante C, Escobar C and Hernández LE (2014) Are plant endogenous factors like ethylene modulators of the early oxidative stress induced by mercury? Front. Environ. Sci. 2:34. doi: 10.3389/fenvs.2014.00034 This article was submitted to Environmental Toxicology, a section of the journal Frontiers in Environmental Science.

Copyright (c) 2014 Montero-Palmero, Ortega-Villasante, Escobar and Hernández. This is an open-access article distributed under the terms of the Creative Commons Attribution License (CC BY). The use, distribution or reproduction in other forums is permitted, provided the original author(s) or licensor are credited and that the original publication in this journal is cited, in accordance with accepted academic practice. No use, distribution or reproduction is permitted which does not comply with these terms. 